\title{
Sevoflurane and nephrogenic diabetes insipidus on the rise: copeptin to the rescue?
}

\author{
Patrick M. Honore ${ }^{1 *}$, David De Bels ${ }^{1}$, Leonel Barreto Gutierrez', Sebastien Redant ${ }^{1}$, Andrea Gallerani ${ }^{1}$ and \\ Willem Boer ${ }^{2}$
}

This comment refers to the article available at https://doi.org/10.1186/s13054-018-1955-7.

With interest, we read the recent paper by Nigro et al. on the differential diagnosis of hypernatremia in intensive care unit (ICU) [1]. One of their main findings was an evidently higher copeptin levels in nephrogenic diabetes insipidus (NDI), compared to central diabetes insipidus (CDI). When choosing a cutoff value of $<4.4 \mathrm{pmol} / \mathrm{L}$, copeptin levels had a sensitivity of $100 \%$ and a specificity of $99 \%$ for diagnosing CDI, whereas the values for NDI were approximately 18 times higher [1]. These findings confirmed the results of an earlier study by Timper et al. [2]. While the authors claim that the incidence of NDI remains very low, this may change with the increasing use of sevoflurane in ICU, which appears to be effective in reducing wake-up and extubation times and was recently described for sedation in acute respiratory distress syndrome [3]. In a recent retrospective study, of the 35 patients receiving sevoflurane, seven patients presented with NDI during their ICU stay (i.e., 20\%) [3]. The main finding of this study was that sevoflurane sedation in ICU was associated with NDI in relation to concentration and duration of exposure. All patients with NDI were sedated with mean end-tidal concentration of sevoflurane $>1.0 \mathrm{vol} \%$ and for more than $72 \mathrm{~h}$. Cabibel et al. also described the occurrence of three cases of NDI after 4 days or more of $1 \mathrm{vol} \%$ end-tidal sevoflurane administration [4]. It is thought that sevoflurane temporarily reduces urinary concentration capacity mechanisms allowing aquaporin 2 expression on cellular membranes [5]. Alternatively inorganic fluoride produced with hexafluoroisopropanolol during sevoflurane metabolism by cytochrome P450 may be toxic [4]. The differential diagnosis between NDI and CDI can be problematic as both groups may present with

\footnotetext{
* Correspondence: Patrick.Honore@CHU-Brugmann.be

${ }^{1}$ ICU Department, Centre Hospitalier Universitaire Brugmann, Place Van

Gehuchtenplein, 4, Brussels, Belgium

Full list of author information is available at the end of the article
}

neurological problems [1]. Only a trial dose of desmopressin could differentiate as most but not all with NDI will remain unresponsive [3,4]. Copeptin may resolve the diagnosis dilemma [1] allowing institution of appropriate treatment, either by removal of the cause (sevoflurane) or the treatment of the causality (brain edema, cerebral bleeding, etc.). In summary, as long as sevoflurane use increases and in the knowledge that $20 \%$ of these cases develop NDI, copeptin is a valuable tool permitting a rapid and definitive differential diagnosis between CDI and NDI.

\section{Abbreviations \\ ICU: Intensive care unit; NDI: Nephrogenic diabetes insipidus; CDI: Central diabetes insipidus}

\section{Acknowledgements \\ None.}

\section{Authors' contributions}

PMH and WB designed the paper. All authors participated in drafting and reviewing. All authors read and approved the final version of the manuscript.

\section{Funding}

None.

Availability of data and materials Not applicable.

Ethics approval and consent to participate Not applicable.
Consent for publication
Not applicable.
Competing interests
The authors declare that they have no competing interests.

\section{Author details}
${ }^{1}$ ICU Department, Centre Hospitalier Universitaire Brugmann, Place Van Gehuchtenplein, 4, Brussels, Belgium. ${ }^{2}$ Department of Anesthesiology, Intensive Care Medicine, Emergency Medicine \& Pain Medicine, Ziekenhuis Oost-Limburg, Genk, Belgium. 
Received: 28 July 2019 Accepted: 29 August 2019

Published online: 05 September 2019

\section{References}

1. Nigro N, Winzeler B, Suter-Widmer I, Schuetz P, Arici B, Bally M. Copeptin levels and commonly used laboratory parameters in hospitalised patients with severe hypernatraemia - the "co-MED study". Crit Care. 2018;22(1):33. https://doi.org/10.1186/s13054-018-1955-7.

2. Timper K, Fenske W, Kuhn F, et al. Diagnostic accuracy of copeptin in the differential diagnosis of the polyuria-polydipsia syndrome: a prospective multicenter study. J Clin Endocrinol Metab. 2015;100(6):2268-74.

3. L'Heudé $M$, Poignant S, Elaroussi $D$, Espitalier F, Ferrandière $M$, Laffon $M$. Nephrogenic diabetes insipidus associated with prolonged sedation with sevoflurane in the intensive care unit. Br J Anaesth. 2019;122(5):e73-5. https://doi.org/10.1016/j.bja.2019.02.009 Epub 2019 Mar 11.

4. Cabibel R, Gerard L, Maiter D, Collin V, Hantson P. Complete nephrogenic diabetes insipidus after prolonged sevoflurane sedation: a case report about 3 cases. A A Pract. 2019;12(5):155e9 [Report].

5. Morita K, Otsuka F, Ogura T, et al. Sevoflurane anaesthesia causes a transient decrease in aquaporin-2 and impairment of urine concentration. $\mathrm{Br} J$ Anaesth. 1999;83:734e9.

\section{Publisher's Note}

Springer Nature remains neutral with regard to jurisdictional claims in published maps and institutional affiliations. 